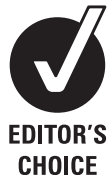

CHOICE

\title{
Effect of pupil size on uncorrected visual acuity in astigmatic eyes
}

\author{
Kazutaka Kamiya, ${ }^{1}$ Hidenaga Kobashi, ${ }^{1}$ Kimiya Shimizu, ${ }^{1}$ Takushi Kawamorita, ${ }^{2}$ \\ Hiroshi Uozato ${ }^{2}$
}

1 Department of Ophthalmology, University of Kitasato School of Medicine, Kanagawa, Japan ${ }^{2}$ Department of Orthoptics and Visual Science, School of Allied Health Sciences, University of Kitasato, Kanagawa, Japan

\section{Correspondence to}

Kazutaka Kamiya, Department of Ophthalmology, University of Kitasato School of Medicine, 1-15-1 Kitasato, Sagamihara, Kanagawa 228-8555, Japan; kamiyak-tky@umin.ac.jp

Accepted 28 March 2011 Published Online First 21 April 2011

\section{ABSTRACT}

Aim To determine the effects of pupil size on uncorrected visual acuity (UCVA) in astigmatic eyes.

Methods The authors examined 20 normal eyes of 20 healthy volunteers (age $26.7 \pm 4.9$ years (mean $\pm S D$ ); 8 men, 12 women). After fully correcting cycloplegic refraction, the authors created with-the-rule and against-the-rule astigmatism of 1, 2, and 3 dioptres (D) in each eye, and then assessed UCVA using artificial pupils ( 1 to $5 \mathrm{~mm}$ ) in these astigmatic eyes. Measurements were performed three times, and the mean value was used for statistical analysis.

Results In eyes with with-the-rule astigmatism of 1,2 and 3 D, logMAR UCVA was $0.04 \pm 0.08,0.09 \pm 0.09$ and $0.16 \pm 0.16$ for $1 \mathrm{~mm}$ pupils, $-0.01 \pm 0.09,0.12 \pm 0.15$ and $0.33 \pm 0.24$ for $2 \mathrm{~mm}$ pupils, $0.02 \pm 0.09,0.20 \pm 0.19$ and $0.46 \pm 0.30$ for $3 \mathrm{~mm}$ pupils, $0.02 \pm 0.08$, $0.24 \pm 0.20$ and $0.48 \pm 0.21$ for $4 \mathrm{~mm}$ pupils, and $0.08 \pm 0.10,0.33 \pm 0.18$ and $0.53 \pm 0.22$ for $5 \mathrm{~mm}$ pupils, respectively. The variance of the data was statistically significant $(p=0.03$ for $1 D, p<0.001$ for $2 D, p<0.001$ for $3 \mathrm{D}$, analysis of variance). Similar results were obtained in eyes with against-the-rule astigmatism. Conclusions Both the amount of astigmatism and the pupil size can affect UCVA in astigmatic eyes. It is suggested that not only the amount of astigmatism but also the pupil size should be taken into consideration for acquiring better visual performance in astigmatic eyes.

\section{INTRODUCTION}

Since astigmatic errors can lead to both a decrease in uncorrected visual acuity (UCVA) and deterioration of quality of vision, reducing this pre-existing astigmatism and acquiring good visual outcomes are two essentials for minimising spectacle dependence and maximising subsequent patient satisfaction. Several surgical options for the correction of astigmatism have been advocated, such as laser in situ keratomileusis, photorefractive keratectomy, astigmatic keratotomy using limbal or corneal relaxing incisions, the use of a toric phakic or pseudophakic intraocular lens, and other excimer laser refractive procedures. At present, we merely consider the amount of astigmatism as well as the axis of astigmatism for these surgical approaches. However, it is known that pupil size plays an important role in the refractive outcomes of the surgical procedure. ${ }^{1-5}$ To our knowledge, the effects of pupil diameter on visual performance in astigmatic eyes have not been investigated so far and still remain unclear. The purpose of this study is to prospectively evaluate the effects of pupil size on visual acuity in eyes with astigmatism.

\section{MATERIALS AND METHODS}

Twenty eyes of 20 healthy volunteers (eight men and 12 women; ages 26.7 \pm 4.9 years (mean age $\pm \mathrm{SD}$; range, from 22 to 37 years old)) who had no ophthalmic diseases other than refractive errors were enrolled in this prospective study. The manifest refraction (spherical equivalent) was $-1.69 \pm 2.20$ dioptres (D) (range -6.25 to $0.75 \mathrm{D}$ ). The manifest refractive cylinder was $-0.11 \pm 0.25 \mathrm{D}$ (range -0.75 to $0.00 \mathrm{D}$ ). Corneal and ocular higherorder aberrations (HOAs) determined using Hartmann-Shack aberrometry (KR-9000, Topcon, Tokyo, Japan) were $0.06 \pm 0.02 \mu \mathrm{m}$ (range 0.04 to $0.10 \mu \mathrm{m}$ ), and $0.10 \pm 0.02 \mu \mathrm{m}$ (range 0.05 to $0.16 \mu \mathrm{m}$ ) for a $4 \mathrm{~mm}$ pupil, respectively. Eyes with keratoconus were excluded from the study by using the keratoconus screening test of Placido disk videokeratography (TMS-2, Tomey, Nagoya, Japan). Informed consent was obtained from all volunteers in accordance with institutional guidelines, according to the tenets of the Declaration of Helsinki.

After corneal anaesthesia was obtained using one drop of oxybuprocaine (Benoxil; Santen, Osaka, Japan), cycloplegia was achieved with three drops of 1\% cyclopentolate hydrochloride (Cyplegin; Santen), spaced 5 min apart. ${ }^{6} 7$ Autorefraction (ARK-700A; Nidek, Gamagori, Japan) was undertaken at least 30 min after the third administration of cyclopentolate hydrochloride and only if the pupillary light reflex was absent. After fully correcting cycloplegic refraction, we produced with-the-rule (WTR) (axis $90^{\circ}$ ) and against-the-rule (ATR) (axis $0^{\circ}$ ) astigmatism of 1,2 and $3 \mathrm{D}$ in each eye. We assessed UCVA using artificial pupils (1 to $5 \mathrm{~mm}$ ) in these eyes. Only right eyes were tested. We carried out this measurement three times, and the average value was used for the analysis.

All statistical analyses were performed using SPSS. Repeated-measures analysis of variance (ANOVA), followed by the Dunnett post hoc test for multiple comparisons, was used to compare the differences between groups with different pupil sizes. The results are expressed as mean $\pm S D$, and a $p$ value of $<0.05$ was considered statistically significant.

\section{RESULTS}

In eyes with a WTR astigmatism of $1 \mathrm{D}$, logMAR UCVA was $0.04 \pm 0.08,-0.01 \pm 0.09,0.02 \pm 0.09$, $0.02 \pm 0.08$ and $0.08 \pm 0.10$, for $1,2,3,4$ and $5 \mathrm{~mm}$ pupils, respectively (figure 1 ). The variance of the data was statistically significant ( $p=0.03$, ANOVA). Multiple comparisons demonstrated a significant 


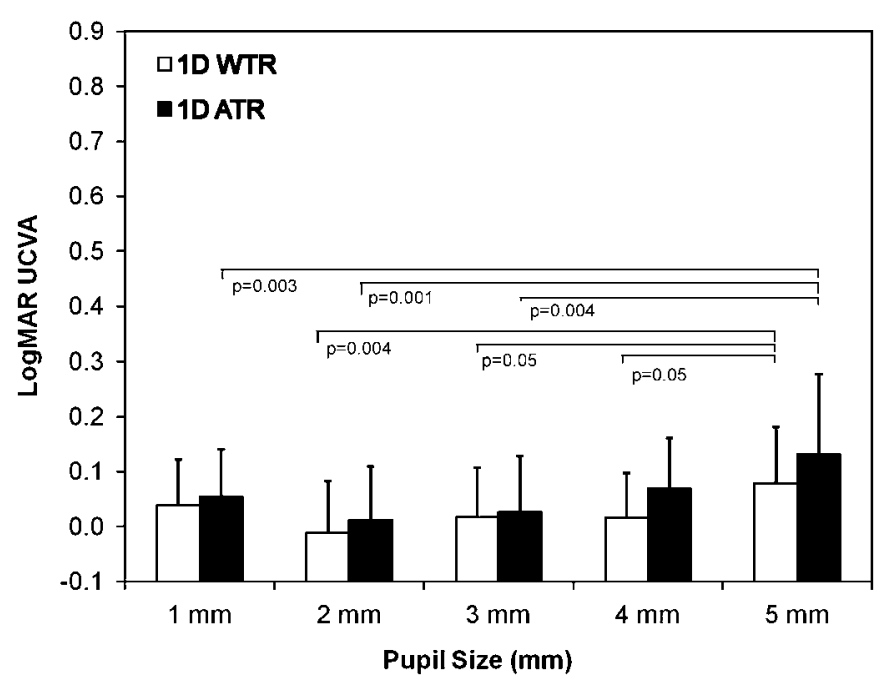

Figure 1 Uncorrected visual acuity (UCVA) as a function of pupil diameter in eyes with 1 dioptres of with-the-rule (WTR) and against-therule (ATR) astigmatism.

difference between measurements made for a $2 \mathrm{~mm}$ pupil and for a $5 \mathrm{~mm}$ pupil ( $\mathrm{p}=0.004$, Dunnett test), for a $3 \mathrm{~mm}$ pupil and a $5 \mathrm{~mm}$ pupil $(\mathrm{p}=0.05)$, and for a $4 \mathrm{~mm}$ pupil and a $5 \mathrm{~mm}$ pupil $(p=0.05)$, but no significant differences between those made for a $1 \mathrm{~mm}$ pupil and a $5 \mathrm{~mm}$ pupil $(\mathrm{p}=0.21)$. In eyes with a WTR astigmatism of $2 \mathrm{D}$, logMAR UCVA was $0.09 \pm 0.09,0.12 \pm 0.15$, $0.20 \pm 0.19,0.24 \pm 0.20$ and $0.33 \pm 0.18$, for $1,2,3,4$ and $5 \mathrm{~mm}$ pupils, respectively (figure 2). The variance of the data was statistically significant $(p<0.001$, ANOVA). Multiple comparisons demonstrated a significant difference between measurements made for a $1 \mathrm{~mm}$ pupil and for a $5 \mathrm{~mm}$ pupil $(\mathrm{p}<0.001)$, for a $2 \mathrm{~mm}$ pupil and a $5 \mathrm{~mm}$ pupil $(\mathrm{p}<0.001)$, and for a $3 \mathrm{~mm}$ pupil and a $5 \mathrm{~mm}$ pupil $(\mathrm{p}=0.02)$, but no significant differences between those made for a $4 \mathrm{~mm}$ pupil and a $5 \mathrm{~mm}$ pupil $(p=0.13)$. In eyes with WTR astigmatism of $3 D, \log M A R$ UCVA was $0.16 \pm 0.16,0.33 \pm 0.24,0.46 \pm 0.30,0.48 \pm 0.21$ and $0.53 \pm 0.22$, for $1,2,3,4$ and $5 \mathrm{~mm}$ pupils, respectively (figure 3 ). The variance of the data was statistically significant $(p<0.001$, ANOVA). Multiple comparisons demonstrated a significant

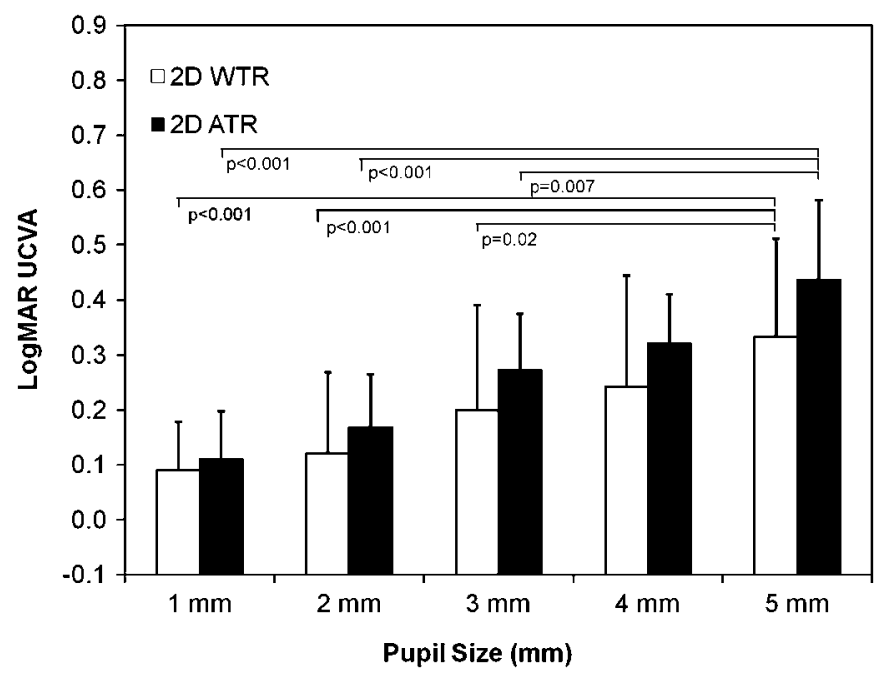

Figure 2 Uncorrected visual acuity (UCVA) as a function of pupil diameter in eyes with 2 dioptres of with-the-rule (WTR) and against-therule (ATR) astigmatism.

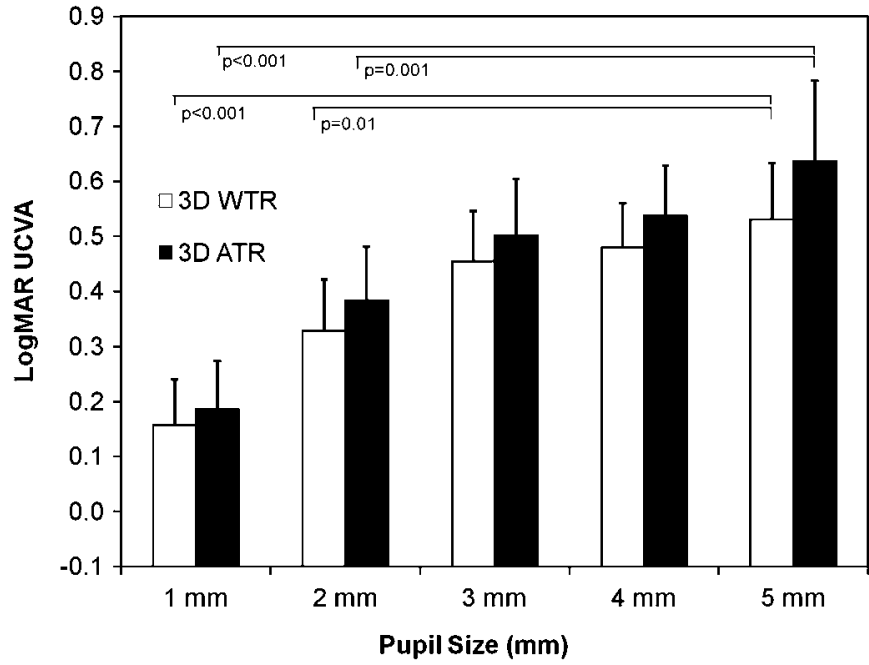

Figure 3 Uncorrected visual acuity (UCVA) as a function of pupil diameter in eyes with 3 dioptres of with-the-rule (WTR) and against-therule (ATR) astigmatism.

difference between measurements made for a $1 \mathrm{~mm}$ pupil and a $5 \mathrm{~mm}$ pupil $(\mathrm{p}<0.001)$, and for a $2 \mathrm{~mm}$ pupil and a $5 \mathrm{~mm}$ pupil $(p=0.01)$, but no significant differences between those made for a $3 \mathrm{~mm}$ pupil and a $5 \mathrm{~mm}$ pupil $(\mathrm{p}=0.36)$, or for a $4 \mathrm{~mm}$ pupil and a $5 \mathrm{~mm}$ pupil $(\mathrm{p}=0.51)$.

Similarly, in eyes with an ATR astigmatism of $1 \mathrm{D}, \log \mathrm{MAR}$ UCVA was $0.05 \pm 0.09,0.01 \pm 0.10,0.03 \pm 0.10,0.07 \pm 0.09$ and $0.13 \pm 0.15$, for $1,2,3,4$ and $5 \mathrm{~mm}$ pupils, respectively (figure 1 ). The variance of the data was statistically significant $(p=0.006$, ANOVA). Multiple comparisons demonstrated a significant difference between measurements made for a $1 \mathrm{~mm}$ pupil and for a $5 \mathrm{~mm}$ pupil ( $\mathrm{p}=0.03$ ), for a $2 \mathrm{~mm}$ pupil and a $5 \mathrm{~mm}$ pupil $(\mathrm{p}=0.001)$, and for a $3 \mathrm{~mm}$ pupil and a $5 \mathrm{~mm}$ pupil $(\mathrm{p}=0.004)$, but no significant differences between those made for a $4 \mathrm{~mm}$ pupil and a $5 \mathrm{~mm}$ pupil $(\mathrm{p}=0.10)$. In eyes with ATR astigmatism of $2 \mathrm{D}, \log \mathrm{MAR}$ UCVA was $0.11 \pm 0.10,0.17 \pm 0.15,0.27 \pm 0.20$, $0.32 \pm 0.19$ and $0.44 \pm 0.22$, for $1,2,3,4$ and $5 \mathrm{~mm}$ pupils, respectively (figure 2 ). The variance of the data was statistically significant $(p<0.001$, ANOVA). Multiple comparisons demonstrated a significant difference between measurements made for a $1 \mathrm{~mm}$ pupil and for a $5 \mathrm{~mm}$ pupil $(\mathrm{p}<0.001)$, for a $2 \mathrm{~mm}$ pupil and a $5 \mathrm{~mm}$ pupil $(\mathrm{p}<0.001)$, and for a $3 \mathrm{~mm}$ pupil and a $5 \mathrm{~mm}$ pupil $(p=0.007)$, but no significant differences between those made for a $4 \mathrm{~mm}$ pupil and a $5 \mathrm{~mm}$ pupil $(\mathrm{p}=0.06)$. In eyes with ATR astigmatism of $3 \mathrm{D}, \log M A R$ UCVA was $0.19 \pm 0.14$, $0.38 \pm 0.23,0.50 \pm 0.26,0.54 \pm 0.24$ and $0.64 \pm 0.23$, for $1,2,3,4$ and $5 \mathrm{~mm}$ pupils, respectively (figure 3 ). The variance of the data was statistically significant $(p<0.001$, ANOVA). Multiple comparisons demonstrated a significant difference between measurements made for a $1 \mathrm{~mm}$ pupil and for a $5 \mathrm{~mm}$ pupil $(p<0.001)$, and for a $2 \mathrm{~mm}$ pupil and a $5 \mathrm{~mm}$ pupil $(\mathrm{p}=0.001)$, but no significant difference between those made for a $3 \mathrm{~mm}$ pupil and a $5 \mathrm{~mm}$ pupil $(\mathrm{p}=0.09)$, or for a $4 \mathrm{~mm}$ pupil and a $5 \mathrm{~mm}$ pupil $(\mathrm{p}=0.22)$.

\section{DISCUSSION}

The results of our study have revealed that UCVA was better in eyes with smaller pupil sizes in almost all cases in which both WTR and ATR astigmatism was present, which was in good agreement with their previous studies on non-astigmatic eyes that showed that eyes with larger pupil sizes tended to have 
a lower UCVA, ${ }^{8-10}$ indicating that pupil size plays an essential role in visual performance in astigmatic eyes as well as in nonastigmatic eyes. Especially in eyes with larger pupils, it may be necessary to correct the pre-existing astigmatism in order to acquire excellent visual outcomes. Our results have also revealed that UCVA was better in eyes with less astigmatism in both WTR and ATR astigmatic eyes. It is quite reasonable that it was in line with previous studies that eyes with a greater astigmatism had lower UCVA. ${ }^{11} 12$ We suggest that not only the amount of astigmatism but also pupil diameter may play an important role in determining UCVA, which is an important factor for minimising spectacle dependence and maximising subsequent patient satisfaction in astigmatic eyes. The human visual system is known to suffer from aberrations, diffraction, scatter, finite receptor size and noise in the neural pathways. The smaller pupil size may have some advantages in its superiority for image formation, such as an increasing depth of focus, a decrease in HOAs ${ }^{13}{ }^{14}$ and a decrease in light scatter, ${ }^{15}$ all of which may, to some extent, offset the deleterious effects of reduced luminance ${ }^{16}$ and diffraction. Accordingly, the smaller pupil may moderate the impact of astigmatic defocus. It is not only the amount of astigmatism or the axis of astigmatism that should be taken into consideration for the surgical correction of cylindrical errors, but also the pupil diameter.

Interestingly, UCVA is highest not for $1 \mathrm{~mm}$ pupil but for $2 \mathrm{~mm}$ pupils in eyes with WTR and ATR astigmatism of $1 \mathrm{D}$, whereas UCVA is highest for $1 \mathrm{~mm}$ pupils in eyes with WTR and ATR astigmatism of 2 and $3 \mathrm{D}$. Atchison et a ${ }^{8}$ demonstrated that the maximum visual acuity occurred for $2-3 \mathrm{~mm}$ diameter pupils, but that larger pupils reduced acuity only marginally in non-astigmatic eyes. Strang et $a l^{13}$ reported that the contrast sensitivity function with a larger pupil was better than that with a smaller pupil at some spatial frequencies, owing to the complex interactions between pupil size and defocusing. The optical modulation transfer function of the human eye has been reported to be equivalent to that of the perfect diffraction system-limited system at a pupil diameter of $1 \mathrm{~mm}$ but not of 1.5 or $2 \mathrm{~mm}^{14} 151718$ Although the exact reason still remains unclear, the authors assume that the pupil-dependent effect of increasing depth of focus, and a decrease in HOAs and light scatter, on UCVA may be larger than the counteractive effect of diffraction and reduced luminance for a $1 \mathrm{~mm}$ pupil, not in eyes with low astigmatism, but in eyes with high astigmatism.

It has been shown that pupil size can be influenced not only by patient background, for example by age, ${ }^{19-25}$ manifest refraction ${ }^{26}$ and the accommodative state of the eye, ${ }^{27} 28$ and by various sensory and emotional conditions, ${ }^{29}$ but also by measurement conditions affecting the level of retinal illuminance. ${ }^{30} 31$ This measurement does not necessarily offer a high reproducibility. However, we used artificial pupils, which were not at all influenced by these factors, at the spectacle plane. The artificial pupils may be useful for determining the exact role of pupil size in visual performance in such eyes. ${ }^{32}$

There are several limitations to this study. First, we examined younger populations who often show WTR astigmatism in this study, and thus this study does not actually reflect the status of any population having some astigmatism. In addition, younger people frequently have a larger pupil, ${ }^{19-25}$ which contributes to larger HOAs and higher retinal luminance levels. Second, in the present study, we measured only HOAs for a $4 \mathrm{~mm}$ pupil, and did not investigate other factors that can affect visual performance in these astigmatic eyes. Since the level of HOAs appears to be low and almost equivalent in all eyes, as shown in the results, we assume that $\mathrm{HOAs}$ did not significantly influence the visual outcomes in this study. A further study is needed in order to clarify the exact role of HOAs and other factors on visual outcomes in eyes having cylindrical errors. Third, we measured only high-contrast visual acuity under photopic conditions (250 lux) with monocular vision, and so our measurements in this study do not accurately reflect natural binocular viewing conditions. However, these natural viewing conditions may include not only the photopic but also the mesopic conditions under which we assessed the pupil size. We are currently conducting a further study to assess pupil size under natural viewing conditions without occlusion.

In conclusion, our study revealed that not only the amount of astigmatism but also the pupil size can affect UCVA in WTR and ATR astigmatic eyes, suggesting that not only the amount of astigmatism but also pupil size should be taken into consideration in order to acquire better visual performance in eyes with astigmatism. Especially in eyes with larger pupils, it may be necessary to correct the pre-existing astigmatism to acquire excellent visual outcomes. We believe that these findings, although simple, are clinically important because most surgeons merely consider the amount of astigmatism and the axis of astigmatism for the surgical correction of astigmatism in a clinical setting. A further study with greater numbers of subjects is required to confirm these preliminary findings.

\section{Competing interests None.}

Patient consent Obtained.

Ethics approval Ethics approval was provided by the Local Ethics Committee.

Provenance and peer review Not commissioned; externally peer reviewed.

\section{REFERENCES}

1. Applegate RA. Glenn Fry award lecture 2002: wavefront sensing, ideal corrections, and visual performance. Optom Vis Sci 2004;81:167-77.

2. Hayashi K, Hayashi H, Nakao F, et al. Correlation between papillary size and intraocular lens decentration and visual acuity of a zonal-progressive multifocal lens and a monofocal lens. Ophthalmology 2001;108:2011-17.

3. Caporossi A, Martone G, Casprini F, et al. Prospective randomized study of clinical performance of 3 aspheric and 2 spherical intraocular lenses in 250 eyes. J Refract Surg 2007;23:639-48.

4. Ito M, Shimizu K, Amano R, et al. Assessment of visual performance in pseudophakic monovision. J Cataract Refract Surg 2009;35:710-14.

5. Oshika T, Tokunaga T, Samejima T, et al. Influence of pupil diameter on the relation between ocular higher-order aberration and contrast sensitivity after laser in situ keratomileusis. Invest Ophthalmol Vis Sci 2006;47:1334-8.

6. Talley DK, Bartlett JD. Topical and regional anesthesia. In: Bartlett JD, Jaanus SD, eds. Clinical Ocular Pharmacology. Boston: Butterworth-Heinemann, 1995:463-77.

7. Siu AW, Sum AC, Lee DT, et al. Prior topical anesthesia reduces time to full cycloplegia in Chinese. Jpn J Ophthalmol 1999:43:466-71.

8. Atchison DA, Smith G, Efron N. The effect of pupil size on visual acuity in uncorrected and corrected myopia. Am J Optom Physiol Opt 1979;56:315-23.

9. Aguilar M, Felipe A, Artigas JM. Coherence of light and visual acuity: the influence of the pupil. Atti Fond G Ronchi 1986;41:81-97.

10. Goodman JW. Introduction to Fourier Optics. 2nd edn. New York: McGraw-Hill, 1996:137-45.

11. Mithcell DE, Wilkinson F. The effect of early astigmatism on the visual resolution of gratings. J Physiol 1974;243:739-56.

12. Pujol J, Arjona M, Arasa J, et al. Influence of amount and changes in axis of astigmatism on retinal image quality. J Opt Soc Am A Opt Image Sci Vis 1998:15:2514-21.

13. Strang NC, Atchison DA, Woods RL. Effects of defocus and pupil size on human contrast sensitivity. Ophthalmic Physiol Opt 1999:19:415-26.

14. Milsom PK, Till SJ, Rowlands G. The effect of ocular aberrations on retinal laser damage thresholds in the human eye. Health Phys 2006;91:20-8.

15. Schwiegerling J. Theoretical limits to visual performance. Surv Ophthalmol 2000;45:139-46.

16. Hersh PS, Schwartz-Goldstein BH. Corneal topography of phase III excimer laser photorefractive keratectomy. Characterization and clinical effects. Summit Photorefractive Keratectomy Topography Study Group. Ophthalmology 1995:102:963-78.

17. Atchison DA, Woods RL, Bradley A. Predicting the effects of optical defocus on human contrast sensitivity. J Opt Soc Am A Opt Image Sci Vis 1998;15:2536-44. 
18. Rovamo J, Kukkonen H, Mustonen J. Foveal optical modulation transfer function of the human eye at various pupil sizes. J Opt Soc Am A Opt Image Sci Vis 1998;15:2504-13.

19. Birren JE, Casperson RC, Botwinick J. Age changes in pupil size. J Gerontol 1955; 5:216-25

20. Kadlecova V, Peleska M, Vasko A. Dependence on age of diameter of the pupil in the dark. Nature 1958;182:1520-1.

21. Seitz R. The dependence on age of the dilation of the dark-adapted pupil. Klin Monbl Augenheilkd 1957:131:48-56.

22. Said FS, Sawires WS. Age dependence of changes in pupil diameter in the dark. Optica Acta 1972;19:359-61.

23. Korczyn AD, Laor N, Nemet P. Sympathetic pupillary tone in old age. Arch Ophthalmol 1976;94:1905-6.

24. Lowenfeld IE. Pupillary changes related to age. In: Topics in Neuro-Ophthalmology. Baltimore, MD: Williams \& Wilkins, 1979:124-50.

25. Koch DD, Samuelson SW, Haft EA, et al. Pupillary size and responsiveness. Implications for selection of a bifocal intraocular lens. Ophthalmology 1991:98:1030-5.
26. Camellin M, Gambino F, Casaro S. Measurement of the spatial shift of the pupil center. J Cataract Refract Surg 2005;31:1719-21.

27. Fry GA. The relation of pupil size to accommodation and convergence. Am J Optom 1945:22:451-65.

28. Marg E, Morgan MW Jr. The pupillary near reflex: The relation of pupillary diamete to accommodation and various components of convergence. Am J Optom 1949;26:183-98.

29. Hess EH. Pupillometrics: A method of studying mental, emotional, and sensory processes. In: Greenfield NS, Sturnbach RA, eds. Handbook of Psychophysiology. New York: Holt, Reinhardt and Winston, 1972:491-534.

30. Wyatt HJ, Musselman JF. Pupillary light reflex in humans: evidence for an unbalanced pathway from nasal retina, and for signal cancellation in brain-stem. Vision Res 1981;21:513-25.

31. Winn B, Whitaker D, Elliott DB, et al. Factors affecting light-adapted pupil size in normal human subjects. Invest Ophthalmol Vis Sci 1994;35:1132-7.

32. Jacobs RJ, Bailey IL, Bullimore MA. Artificial pupils and Maxwellian view. App/ Opt 1992:31:3668-77.

\section{Have confidence in your decision making.}
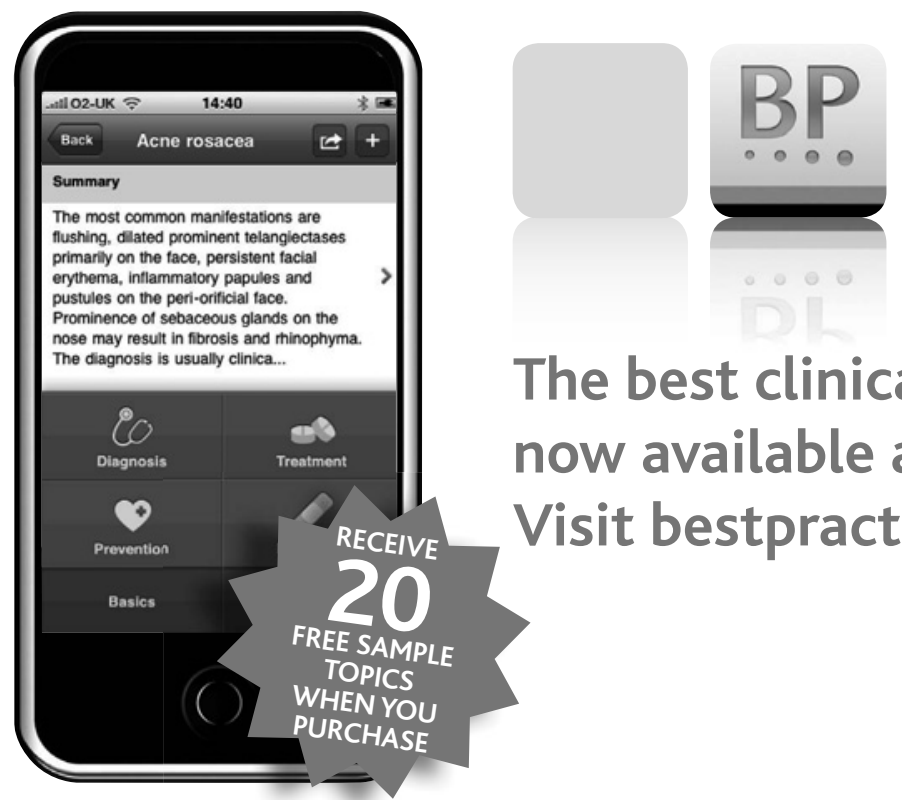

The best clinical decision support tool is now available as an app for your iPhone. Visit bestpractice.bmj.com/app

\section{clinicians $\bullet$ medical students $\bullet$ nurses $\bullet$ healthcare practitioners}

